\title{
The bHLH transcription factor SPATULA regulates root growth by controlling the size of the root meristem
}

\author{
Srilakshmi Makkena ${ }^{1}$ and Rebecca S Lamb $b^{1,2^{*}}$
}

\begin{abstract}
Background: The Arabidopsis thaliana gene SPATULA (SPT), encoding a bHLH transcription factor, was originally identified for its role in pistil development. SPT is necessary for the growth and development of all carpel margin tissues including the style, stigma, septum and transmitting tract. Since then, it has been shown to have pleiotropic roles during development, including restricting the meristematic region of the leaf primordia and cotyledon expansion. Although SPT is expressed in roots, its role in this organ has not been investigated.

Results: An analysis of embryo and root development showed that loss of SPT function causes an increase in quiescent center size in both the embryonic and postembryonic stem cell niches. In addition, root meristem size is larger due to increased division, which leads to a longer primary root. spt mutants exhibit other pleiotropic developmental phenotypes, including more flowers, shorter internodes and an extended flowering period. Genetic and molecular analysis suggests that SPT regulates cell proliferation in parallel to gibberellic acid as well as affecting auxin accumulation or transport.
\end{abstract}

Conclusions: Our data suggest that SPT functions in growth control throughout sporophytic growth of Arabidopsis, but is not necessary for cell fate decisions except during carpel development. SPT functions independently of gibberellic acid during root development, but may play a role in regulating auxin transport or accumulation. Our data suggests that SPT plays a role in control of root growth, similar to its roles in above ground tissues.

\section{Background}

The primary root of Arabidopsis thaliana has a simple and consistent organization of cell types [1]. Roots are divided into three distinct tissue zones along the proximal-distal axis. The most distal area is the zone of cell division or meristematic zone. A zone of cell elongation occurs just proximal to the division zone and the zone of cell differentiation or zone of maturation is the most proximal [2]. Within the root apical meristem (RAM), stem cells surround a group of four mitotically less active cells called the Quiescent Center (QC; [1]). The QC, together with its surrounding four types of stem cells (columella stem cells, epidermal/lateral root cap stem cells, cortex/endodermal stem cells and vascular stem

\footnotetext{
*Correspondence: lamb.129@osu.edu

'Plant Cellular and Molecular Biology Graduate Program, The Ohio State University, Columbus, OH, USA

2Department of Molecular Genetics, The Ohio State University, Columbus, $\mathrm{OH}$, USA
}

\section{Biomed Central}

cells), forms the stem cell niche [3]. The RAM is established during embryogenesis. In Arabidopsis, the zygote divides asymmetrically to form an apical and a basal daughter cell. Three rounds of stereotyped cell divisions in the apical daughter cell give rise to the apical and central regions of the embryo whereas the transverse divisions in the basal cell make about 6-9 cells that make up the extraembryonic suspensor. The uppermost cell of the suspensor becomes the hypophysis, which divides transversely to make an upper and lower hypophyseal cell. The upper hypophyseal cell forms the QC and the lower hypophyseal cell forms the columella stem cells and the central root cap. The rest of the RAM arises from derivatives of the apical cell [3-5].

A complex network of transcription factors regulates specification of the root stem cell niche. The AP2/ERF transcription factor-encoding genes PLETHORA1 (PLT1) and PLT2 are transcribed in response to auxin in the early basal embryo and are redundantly required for QC 
identity and stem cell maintenance [6]. Ectopic embryonic expression of PLT1 and PLT2 can induce the formation of a RAM, including the QC and initial cells [6]. The PLT genes are expressed in a gradient with maximal expression in the stem cell niche promoting stem cell identity and maintenance. Lower levels promote mitotic activity of stem cell daughter cells and low levels promote cell differentiation [7]. Two GRAS family transcription factors, SHORTROOT (SHR) and SCARECROW (SCR), regulate both radial patterning and stem cell niche specification in the root $[8,9]$. SHR is necessary both for the periclinal division of cortex/endodermal initials and endodermal specification [10-13]. SCR is required for the periclinal asymmetric division of the cortical/endodermal initial daughter cells and cell-autonomously required for QC identity $[9,14,15]$.

The SPATULA (SPT) gene encodes a basic helix-loophelix (bHLH) transcription factor and was originally identified for its role in carpel organogenesis [16]. SPT is necessary for the development and proliferation of the carpel margins and for development of tissues derived from the margin $[16,17]$. $S P T$ is partially redundant with the closely related bHLH-encoding gene ALCATRAZ $(A L C)$ and functions during fruit development to specify formation of the valve margin tissue in addition to margin tissues during pistil development. These proteins can heterodimerize and SPT can complement dehiscence defects in alc mutants if expressed appropriately, although the converse is not true [18]. In addition to its interaction with ALC, SPT interacts genetically and physically with another bHLH protein, INDEHISCENT (IND), in both carpel margin and fruit valve specification and these transcription factors may bind common target genes cooperatively [19]. SPT and IND proteins regulate auxin accumulation in the apical region of the developing carpels, important for carpel margin specification. This is due at least in part by their direct regulation of expression of two genes encoding members of the AGC3 family of protein kinases (PID and WAG2) that phosphorylate and control activity of PIN auxin efflux carriers [19].

Although SPT has been most extensively studied in the context of floral development, it has been shown to be involved in seed germination and leaf and cotyledon development [20-23]. SPT has also been shown to mediate vegetative growth repression in response to cool day temperatures [22] and spt mutants have larger leaves due to increased cell numbers and an enlarged meristematic region in leaf primordia [21] and larger cotyledons due to increased cell expansion [23]. Consistent with its broad function, SPT is expressed in proliferating regions of both vegetative and reproductive tissues, including the root $[16,24]$.

Here, we investigate the role of SPT in root growth. spt mutants have longer primary roots due to an increase in cell proliferation. Examination of the RAM of these mutants showed that QC size is increased as is cell division in the initial cells, as measured by the cell division marker $p C Y C B 1 ; 1:: G U S$. The increased QC size arises in the embryo and extra divisions continue throughout root development. The effect of loss of SPT function on root growth is independent of GA but shares some common targets with this hormone. spt mutants show a larger auxin maximum at the root tip. Analysis of the mutants' responses to exogenous auxin and auxin transport inhibitors suggests that auxin transport is likely to be altered. Control of auxin transport may be a common mechanism by which SPT regulates growth in the plant. Our results uncover the importance of SPT in the regulation of RAM size control.

\section{Results}

SPT is necessary for multiple developmental aspects of plant development

Although analysis of SPT function has been confined to the shoot, SPT is expressed in the root as well (Additional file 1; [24]). In order to analyze the possible function of SPT in this region, the root meristem of spt-2 and spt-11 mutants was compared to that of their respective wild types (Landsberg erecta (L. er) and Columbia-0 (Col-0). Throughout the period of our observation, both spt-2 and spt-11 have longer root meristems (defined as the area between the QC and the first elongating cell in the root cortical layer; [25]) when compared to wild type, both as measured by number of cells and by length (Figure 1). Similar results were obtained when expression of the G2-M marker CYCB1;1::GUS [26] was observed. spt-11 root meristems have a larger region of cells expressing this marker when compared to wild type (Additional file 2) and have more cells expressing this marker (an average of 41.3 cells per root vs. 35.2 cells per root in Col-0 ( $\mathrm{n}=15$ seedlings). The primary root lengths of spt-11 plants were longer than wild type (Figure 2A). A similar trend was seen in spt-2 (data not shown); however, due to the tendency of roots to grow aslant and curl on vertical agar plates in the L. er background [27], which makes root measurements more difficult, this background was not as extensively analyzed. Primary root growth rates increase through 7 DAG and decline at 9 DAG, in both wild type and spt-11 mutants, although the growth rate of $s p t-11$ roots was significantly higher than Col-0 (Figure 2B).

We also examined other growth parameters in spt mutants to determine how pleiotropic the function of this gene is. Both $s p t-2$ and $s p t-11$ plants are taller than wild type with more flowers. However, the internodes of these plants are shorter (Table 1). spt-11 plants flowered earlier than Col-0, measured both as number of days to flower and number of leaves (Table 1). In contrast, spt-2 

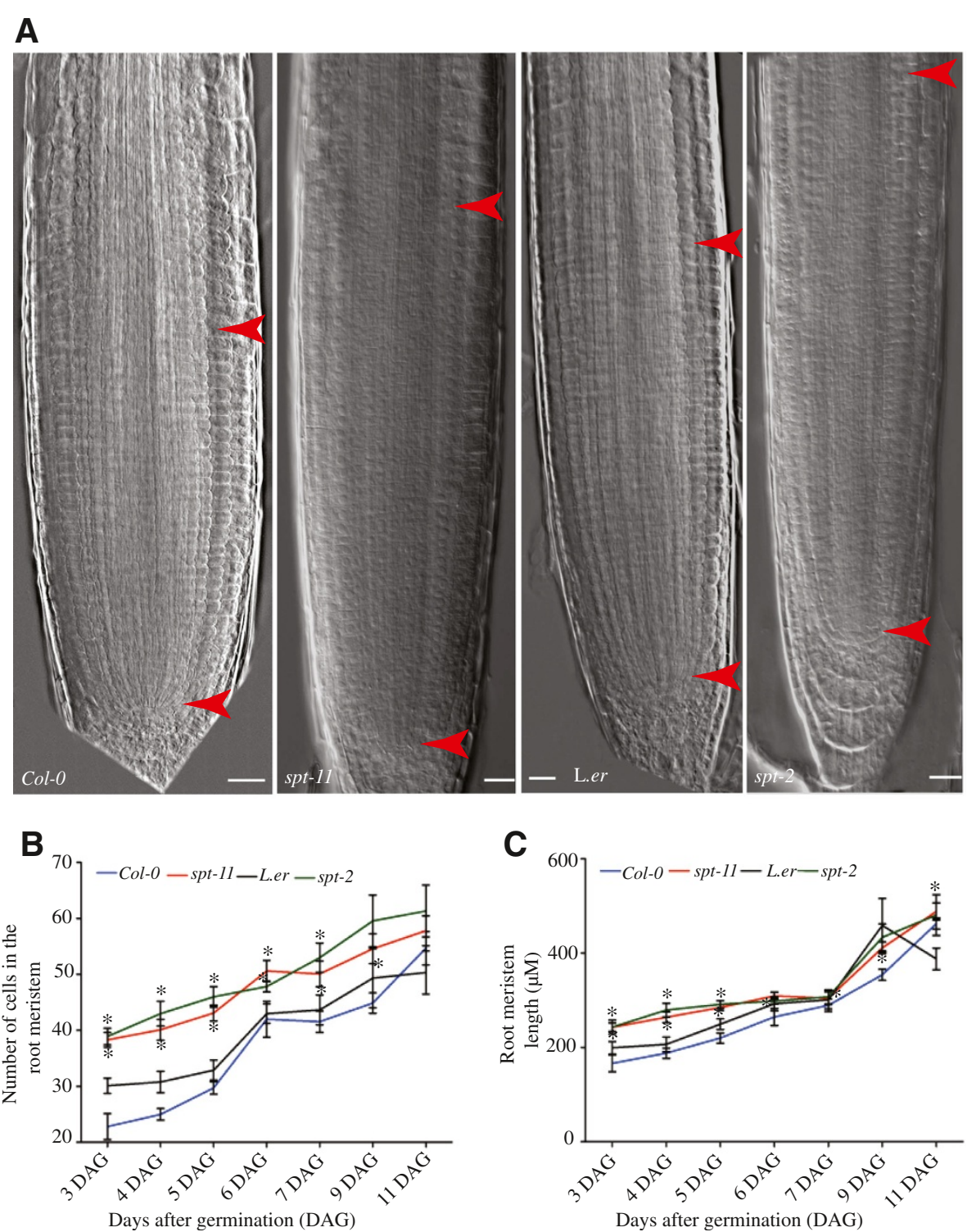

Figure 1 spt mutants have larger RAMs than wild type. (A) Micrographs of 5 DAG roots. Arrowheads indicate the zone of cell division. (B) RAM size expressed as number of cells in the cortex. (C) Length of the RAM. Values are means $(n=15) \pm$ standard error. Asterisks indicate values significantly different from wild type at $\mathrm{P}<0.05$. Scale bars indicate $100 \mu \mathrm{m}$.

plants flowered significantly later than L. er, suggesting that accession specific modifiers of SPT function may exist. Alternatively, the differences in flowering time could be due to the nature of the $S P T$ alleles. $s p t-11$ is a knock down allele caused by a Ds insertion [21] while spt-2 results from a missense mutation that changes an arginine to a lysine within the basic domain, a change that has been shown to abolish DNA binding in other bHLH proteins [16]. The differences in the nature of the alleles may contribute to the differences seen in flowering time in addition to or instead of the strain background.
SPT controls the size of the quiescent center of both the embryonic and postembryonic stem cell niches

We have investigated stem cell organization and number in $s p t$ mutants during the embryonic and postembryonic stages. Our observations of embryos indicate that there is no difference in the number of QC progenitor cells (data not shown) between wild type and spt-11, whereas the number of QC cells in spt-11 differs from Col-0 at later stages of embryo development starting at the late heart stage (Figure 3B, D). In wild type, $90 \%$ of the observed embryos $(n=30)$ had four QC cells in both torpedo and mature embryo stages while the other $10 \%$ 

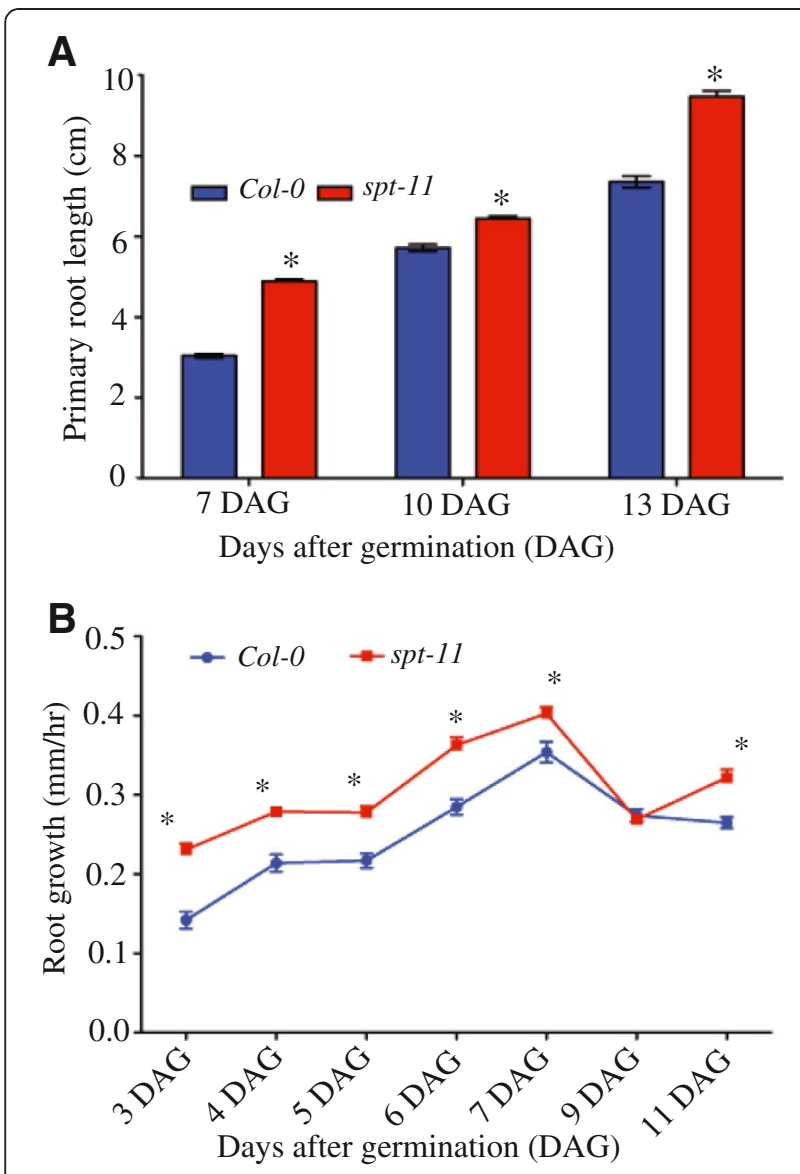

Figure 2 Increased growth of $\boldsymbol{s p t}$ roots. (A) Primary root length $(n=90)$ at 7,10 and 13 DAG. (B) Primary root growth rate $(n=30)$ expressed as $\mathrm{mm} / \mathrm{hr}$. Error bars indicate standard error. Asterisks indicate values significantly different from wild type at $\mathrm{P}<0.05$.

had 6 cells. In spt-11 embryos, only $57 \%$ of the torpedo stage $(n=35)$ and $51.5 \%$ of the mature embryos $(n=35)$ have 4 cells while $43 \%$ and $38.5 \%$ had 6 cells, respectively. The trend in spt-2 is similar (56\% of observed roots had 6 or more cells in the QC $(\mathrm{n}=35))$; however, L. er tends to have more than 4 cells in its QC as well (40\% of observed roots had 6 or greater cells $(n=35)$ ).

Postembryonically, stem cell organization was studied by double staining of root tips for expression of GUS driven by a QC-specific promoter trap, QC25 [28], and starch staining of root cap cells. spt-11 has a single columella stem cell layer as in wild type and the root cap has differentiated normally (Figure 4B, F). However, spt-11 root tips have more cells in the $\mathrm{QC}$ when compared to wild type (Figure 4B, F). In wild type, $81 \%$ of the observed seedlings $(n=32)$ had four cells marked by QC25 expression while the other 19\% had 6 cells in the QC. In spt-11 seedlings only $30 \%$ of the observed seedlings $(n=51)$ have 4 cells displaying QC25 expression while $38 \%$ had 6 cells, $30 \%$ had 8 cells and $2 \%$ had 10 cells in the QC. The increased number of cells in the QC was reflected in a broader QC (with more than two cell across) as well as QCs with more than one layer of cells. A low level of GUS staining driven by QC25 (when compared to QC specific GUS staining) was also observed in the columella stem cell layer of spt-11 root tips (Figure 4F). Consistent with the QC25 results, the columella specific enhancer trap Q1630::GFP also reveals the presence of a single columella stem cell layer in spt-11 (Figure 4D). Starch staining was also used to examine RAM organization in spt-2 and L. er (Figure 4G, H). Consistent with the spt-11 results, spt-2 roots have a single layer of columella stem cells but extra QC cells (Figure $4 \mathrm{H}$ ). This suggests that SPT function helps control the number of cells in the QC both in the embryonic and post embryonic stages, but not distal meristem organization.

\section{Loss of SPT function leads to a broader auxin maximum at the root tip but does not disrupt root patterning}

Auxin accumulates at the distal root primordia and is required for QC and stem cell specification [29]. Previously it has been shown that spt-2 gynoecial phenotypes were partially rescued by the application of the polar auxin transport inhibitor N-1-naphthylphthalmic acid (NPA), suggesting a role for $S P T$ in control of auxin transport [30], presumably through its control of expression of WAG2 and PID [19]. To test whether the auxin distribution or transport are altered in spt mutants, we looked at the expression of the auxin efflux carrier PIN4 [31] and the auxin responsive reporter DR5::GUS, which is used to visualize auxin response maxima [32]. The PIN4p::PIN4-GFP and DR5::GUS transgenes were introduced into the spt-11 background by crossing. PIN4-

Table 1 SPT impacts plant growth ${ }^{\mathrm{a}}$

\begin{tabular}{|c|c|c|c|c|c|c|}
\hline \multirow[t]{2}{*}{ Genotype } & \multicolumn{2}{|c|}{ Flowering time } & \multicolumn{3}{|c|}{ Inflorescence stem } & \multirow[t]{2}{*}{ Total plant height $^{b}$} \\
\hline & $\begin{array}{l}\text { Days to } \\
\text { flower }\end{array}$ & $\begin{array}{l}\text { Number of } \\
\text { rosette leaves }\end{array}$ & $\begin{array}{l}\text { Number } \\
\text { of flowers }\end{array}$ & $\begin{array}{l}\text { Number } \\
\text { of internodes }\end{array}$ & $\begin{array}{l}\text { Length } \\
\text { of internodes }^{b}\end{array}$ & \\
\hline L.er & $22.4 \pm 0.4$ & $17.6 \pm 0.6$ & $49.1 \pm 1.0$ & $51.9 \pm 1.0$ & $0.57 \pm 0.01$ & $30.0 \pm 0.7$ \\
\hline spt-2 & $23.6 \pm 0.3^{c}$ & $27.1 \pm 0.9^{c}$ & $74.5 \pm 1.2^{c}$ & $78.0 \pm 1.3^{c}$ & $0.42 \pm 0.004^{c}$ & $35.0 \pm 0.5^{c}$ \\
\hline Col-0 & $29.9 \pm 0.7$ & $39.3 \pm 1.4$ & $71.7 \pm 2.0$ & $75.0 \pm 1.9$ & $0.83 \pm 0.008$ & $63.2 \pm 1.6$ \\
\hline$s p t-11$ & $28 \pm 0.8$ & $36.8 \pm 1.5$ & $80.8 \pm 2.8^{c}$ & $84.0 \pm 2.6^{c}$ & $0.77 \pm 0.012^{c}$ & $65.8 \pm 1.3$ \\
\hline
\end{tabular}

Values are means \pm standard error. ${ }^{a}$ All plants grown together. ${ }^{\mathrm{b}}$ Measured in centimeters. ${ }^{\mathrm{V}}$ Values significantly different from wild type at $\mathrm{P}<0.05$. 

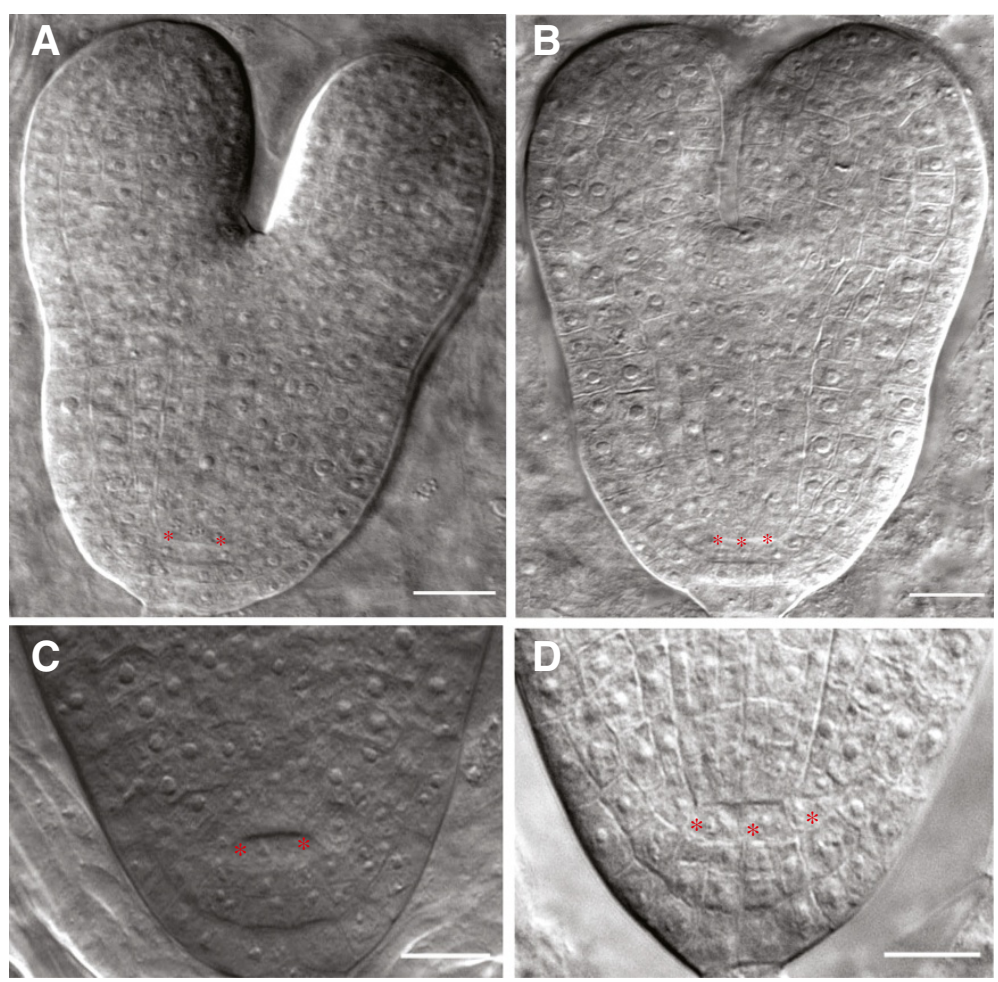

Figure 3 QC size is increased in spt-11 embryos. (A-D) Micrographs of embryos. Asterisks indicate cells in the QC. (A, C) Col-0. (B, D) spt-11. Scale bars indicate $50 \mu \mathrm{m}$.

GFP accumulated in a nonpolar manner in the region of the QC and surrounding cells (Figure 5A). This expression pattern is similar to that documented by Friml et al. [31]; however, significant differences in the pattern of PIN4-GFP accumulation in wild type have been reported [33-35]. However, in our hands the expression is most evident in this region of the root [36]. spt-11 has a broader expression domain of both PIN4 (Figure 5B) and DR5::GUS (Figure 5D) when compared to wild type, suggesting a broader auxin maximum or an increase in auxin sensitivity, which might contribute to a larger QC and RAM in these plants.

In order to determine if loss of SPT function affects auxin sensitivity and/or transport, we tested the sensitivity of spt-11 seedling root growth to the synthetic auxin 1-naphthaleneacetic acid (NAA) and the auxin transport inhibitor NPA. The inhibition of spt-11 root growth by NAA was not significantly different from Col-0 (Table 2), suggesting that the sensitivity to exogenous auxin is not altered in this genetic background. In contrast, spt-11 root growth was significantly more inhibited by NPA than wild type, although the difference became negligible at higher levels of NPA application (Table 3). The stronger DR5::GUS maxima in the spt-11 background, combined with the increased sensitivity of spt-11 root growth to NPA application supports the hypothesis that
SPT may act to regulate polar auxin transport, directly or indirectly.

Root stem cell niche specification and radial patterning are regulated in part by two transcription factors, SHR and SCR [8-10,37]. Since spt-11 has more cells in the QC (Figures 3,4), we looked at the expression of SCR and $S H R$ to see if they are disrupted. $p S C R:: G F P$ is expressed in the endodermal layer, endodermal/cortical initials and QC (Figure 5E; [38]) while pSHR::GFP is expressed in the stelar cells (Figure 5G; [10]) and pSHR:: SHR-GFP is expressed in the stelar tissue, endodermal cell layer, endodermal/cortical initials and QC (Figure 5I; [11]). No differences in the expression domains of these genes were seen in $s p t-11$ when compared to wild type seedlings (Figure 5F, H, J), indicating that SPT does not regulate stem cell niche positioning or radial patterning.

SPT expression has been detected in vascular tissues [39]. In order to check if SPT has any role in the development of vascular elements, we looked at the expression of two vascular markers. Enhancer trap J0121::GFP is specifically expressed in the xylem-associated pericycle cells (Additional file 3A; [40]) and the marker CoYMV:: GFP is specifically expressed in the phloem companion cells (Additional file 3C; [41]). The expression of these markers in spt-11 is similar to wild type expression patterns (Additional file 3B, D), suggesting that loss of $s p t$ 


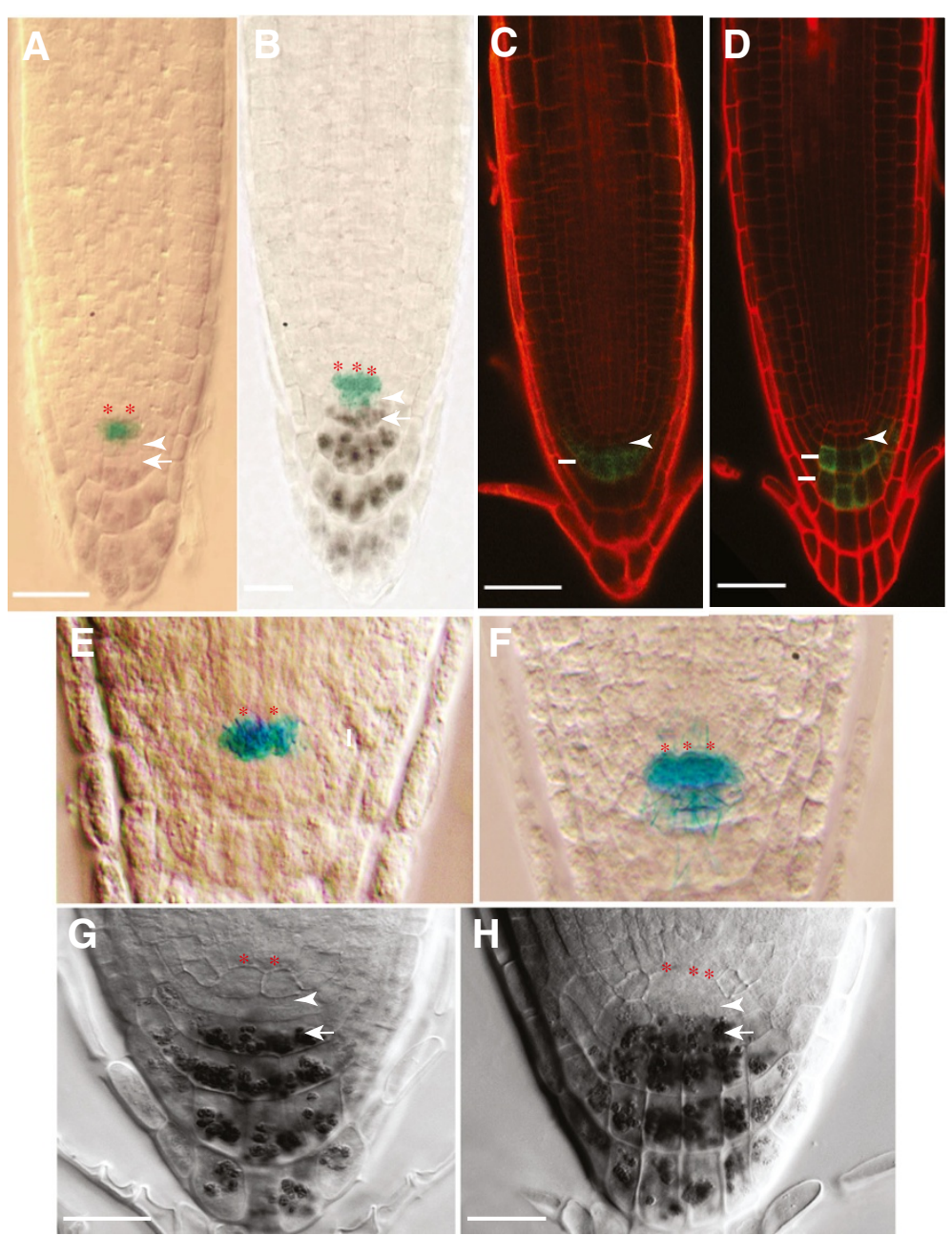

Figure 4 QC size but not patterning is altered in spt-11. Micrographs of 5 DAG roots. (A, C, E) Col-0. (B, D, F) spt-11. (A, B) Expression of QC25::GUS (blue) in the QC and starch in the differentiated columella. Red asterisks indicate QC cells, arrowheads indicate root cap initials and arrows indicate first row of columella cells. (C, D) Expression of the columella marker QC1630::GFP in propidium iodine-stained roots. Arrowheads indicate root cap initial cells and lines indicate stained columella cell layers. $(\mathbf{E}, \mathbf{F})$ Close-ups of the roots shown in A and B to highlight expression of QC25::GUS. Red asterisks indicate QC cells. (G, H) Micrographs of 5 DAG roots stained for starch. (G) L. er. (H) spt-2. Red asterisks appear above cells in the QC. Arrow indicates starch staining in the root cap. Arrowheads indicate columella and epidermal/lateral root cap cells. Scale bars indicate $100 \mu \mathrm{m}$.

does not disrupt differentiation of the vasculature. We also looked at whether the radial organization of the root is affected in spt-11. Col-0 roots have 8 cells in the cortical cell layer (Figure 5K; $\mathrm{n}=15$ seedlings; $>20$ sections/seedling) as previously reported [1], whereas spt-11 roots have 9 cells in the cortical cell layer (Figure 5L; $\mathrm{n}=15$ seedlings; $>20$ sections/seedling), likely reflecting the increased cell division in the root meristem. However, the overall organization of the root is unaffected.

\section{SPT acts in parallel to GA in the root}

GA is known to play a role in regulating RAM size $[42,43]$ and $S P T$ has been implicated in regulation of GA biosynthesis and in GA signalling [20,23] as well as shown to act in parallel to the GA pathway [23]. The relationship between GA and SPT in the root is unknown, however. In order to determine whether spt mutants are responsive to reduced levels of GA, we exposed seedlings to the GA biosynthesis inhibitor paclobutrozol (PAC) and examined the effect on meristem size. As expected, meristem size was reduced in wild type upon exposure to PAC (Figure 6B, E). PAC also reduced meristem size in spt mutants (Figure 6D, E). Interestingly, the response to PAC in L. er roots is not very robust and spt-2 responds more to this inhibitor than L. er (Figure 6E). It has previously been shown that L. er is saturated for GA response in the cotyledons, although it displayed a robust response to PAC in those organs [23]. L. er may have 

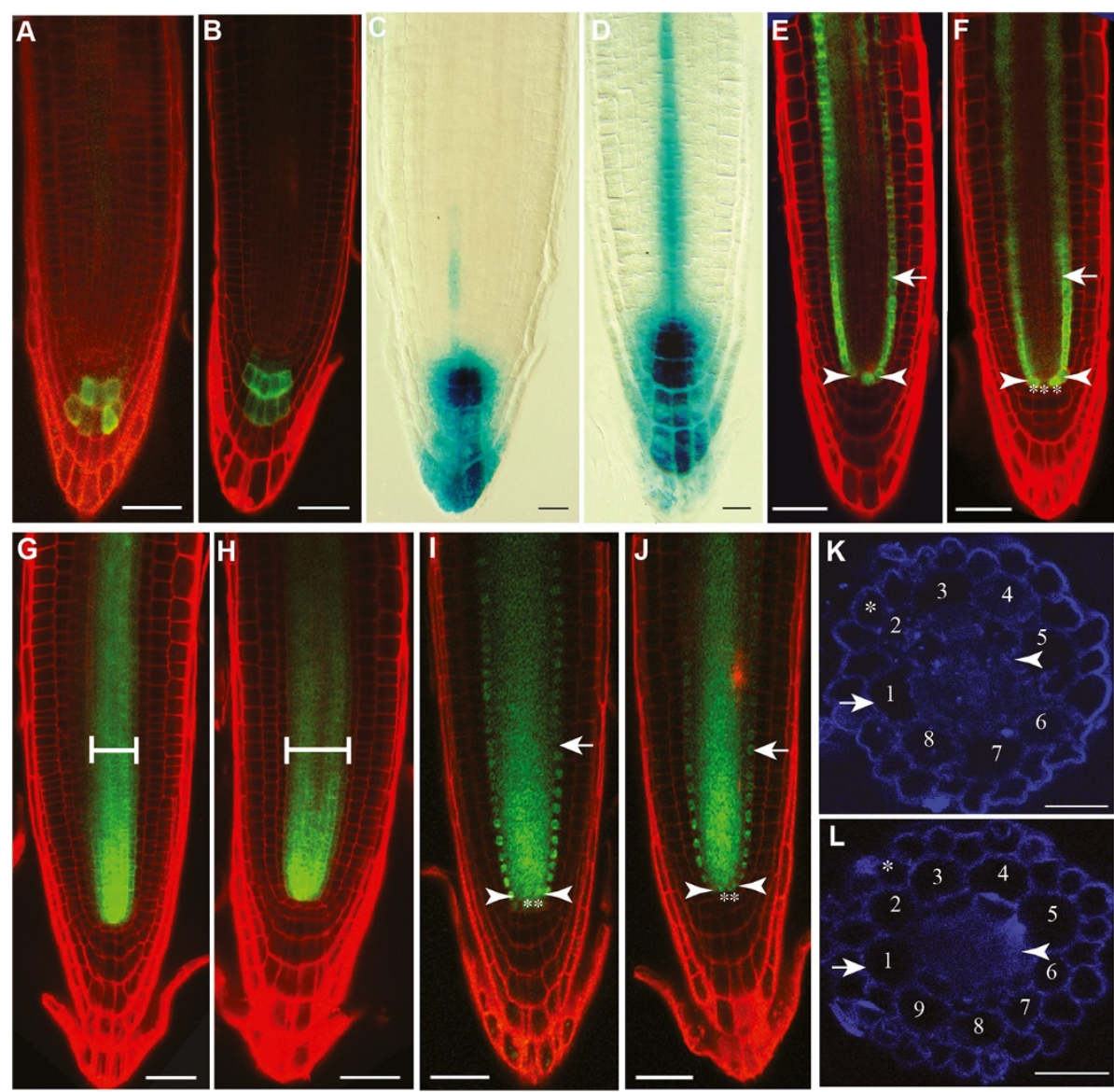

Figure 5 Loss of SPT function alters auxin accumulation but does not disrupt root patterning. (A, B) Confocal micrographs of 5 DAG roots stained with propidium iodide expressing PIN4p::PIN4-GFP. (A) Col-0. (B) spt-11. (C, D) Micrographs of 5 DAG roots expressing DR5::GUS. (C) Col-0. (D) spt-11. (E-J) Confocal micrographs of 5 DAG roots stained with propidium iodide. (E, F) pSCRp::GFP expression. Arrows indicate endodermal cells, asterisks indicate QC cells and arrowheads indicate vascular initials. (E) Col-0. (F) spt-11. (G, H) pSHR::GFP expression. The bracketed region is the stele. (G) Col-0. (H) spt-11. (I-J) pSHR::SHR-GFP expression. Arrows indicate endodermal cells, asterisks indicate QC cells and arrowheads indicate vascular initials. (I) Col-0. (J) spt-11. (K, L) Fluorescent brightener stained free hand cross sections of 7 DAG primary roots. Asterisks indicate the epidermal cell layer. Arrows indicate the cortical cell layer. Arrowheads indicate the endodermal cell layer. Cortical cells are numbered around the diameter. (K) Col-0. (L) spt-11. Scale bars in A-B and D-J indicate $100 \mu \mathrm{m}$. Scale bars in B-C and K-L indicate $50 \mu \mathrm{m}$.

increased levels of GA in roots that buffer its response to GA biosynthetic inhibitors.

To further investigate the relationship between SPTmediated cell proliferation and GA, we crossed spt-11 and spt-2 mutants to GA biosynthesis mutants in the appropriate genetic backgrounds, ga3ox1-2; ga3ox2-1 [44] and ga1-3 [45], respectively. Root meristem size was examined in 7-day-old seedlings of Col-0, spt-11, ga3ox12; ga3ox2-1 and the triple mutant ga3ox1-2; ga3ox2-1; spt-11. The double mutant of ga3ox1-2; ga3ox2-1 has a short RAM, as previously reported (Figure 6H, J; [42]) while spt-11 has the longest RAM among all the genotypes analyzed (Figure 6G, J). The triple mutant ga3ox1-2; ga3ox2-1; spt-11 has a significantly bigger RAM than that of double mutant ga3ox1-2; ga3ox2-1, but a smaller RAM than spt-11 (Figure 6I, J), an additive phenotype. This triple mutant and the ga1-3; spt-2 double mutant were analyzed for other developmental differences. ga3ox1-2; ga3ox2-1; spt-11 plants as well as ga1-3; spt-2 plants are of intermediate height compared to their parents (Additional files 4 and 5). Triple mutants flowered significantly earlier than the ga3ox1-2; ga3ox2-1 plants, have significantly higher number of flowers and internodes, significantly longer internodes and are significantly taller (Additional file 5), suggesting that the loss of SPT function can partially compensate for lower GA levels in the plant. However, the triple mutant plants are neither equivalent to spt11 nor wild type plants. This additive phenotype suggests that SPT and GA act in parallel pathways. The fruit phenotype of spt-11 is still retained in ga3ox1-2; ga3ox2-1; spt- 
Table 2 Response to exogenous NAA is not changed by loss of SPT function

\begin{tabular}{|c|c|c|c|}
\hline Genotype & Concentration of NAA (nM) & Root length (mm) & $\%$ of mock \\
\hline \multicolumn{4}{|l|}{ Col-0 } \\
\hline & 0 & $24.7 \pm 6.7$ & $N A^{a}$ \\
\hline & 1 & $17.1 \pm 4.2$ & $69 \%$ \\
\hline & 20 & $4.6 \pm 1.1$ & $19 \%$ \\
\hline & 40 & $3.4 \pm 1.0$ & $16 \%$ \\
\hline & 60 & $3.1 \pm 0.7$ & $13 \%$ \\
\hline & 80 & $2.7 \pm 0.7$ & $11 \%$ \\
\hline & 100 & $2.2 \pm 0.6$ & $9 \%$ \\
\hline \multicolumn{4}{|l|}{ spt-11 } \\
\hline & 0 & $26.2 \pm 3.7$ & NA \\
\hline & 1 & $17.7 \pm 3.0$ & $68 \%$ \\
\hline & 20 & $5.2 \pm 1.7$ & $20 \%$ \\
\hline & 40 & $4.8 \pm 1.6$ & $18 \%$ \\
\hline & 60 & $3.5 \pm 0.9$ & $13 \%$ \\
\hline & 80 & $3.2 \pm 1.0$ & $12 \%$ \\
\hline & 100 & $2.7 \pm 1.4$ & $11 \%$ \\
\hline
\end{tabular}

Values are means \pm standard deviation. ${ }^{a} \mathrm{NA}$, not applicable.

11 plants (data not shown), suggesting either that GA is not functioning in apical carpel development or that SPT acts downstream of GA in this context.

Endogenous GA levels are regulated by both GA biosynthesis and catabolism/deactivation. GA20-oxidases and GA3-oxidases are each encoded by multi-gene families and catalyze the final steps in GA biosynthesis pathway [46]. These genes are expressed at higher levels in GAdeficient backgrounds and their expression decreases after application of bioactive GAs [47-51]. Endogenous GA levels are regulated by metabolic deactivation and the GA2-oxidases are the best characterized enzymes shown to catalyze such a reaction $[51,52]$. In contrast to the expression of GA biosynthesis genes, GA2-OXIDASE levels go up upon GA application [52-54]. The genes encoding the soluble GA receptors, GID1a and GID1b, whose expression goes down upon GA treatment [52,55], are another marker of GA levels in Arabidopsis. We examined expression of a subset of these genes in 7-dayold seedlings of $s p t$ mutants and their wild types by qPCR analysis. Among the GA biosynthesis genes analyzed, expression of only one (GA3ox1) changed significantly from wild type and only in spt-11, where it was reduced (Figure 7A). Among the GA deactivation pathway genes checked, transcript levels of GA2ox2 was significantly higher in spt-11 and GA2ox4 and GAox8 transcript levels

Table 3 Loss of SPT function confers increased sensitivity to NPA

\begin{tabular}{|c|c|c|c|}
\hline Genotype & Concentration of NPA $(\mu \mathrm{M})$ & Root length (mm) & $\%$ of mock \\
\hline \multicolumn{4}{|l|}{ Col-0 } \\
\hline & 0 & $17.5 \pm 3.3$ & $N A^{a}$ \\
\hline & 0.1 & $9.5 \pm 1.5$ & $55 \%$ \\
\hline & 0.5 & $4.3 \pm 1.0$ & $25 \%$ \\
\hline & 1 & $3.6 \pm 0.7$ & $21 \%$ \\
\hline & $2 \mu \mathrm{M}$ & $2.2 \pm 0.6$ & $13 \%$ \\
\hline \multicolumn{4}{|l|}{ spt-11 } \\
\hline & 0 & $23.4 \pm 2.9^{b}$ & NA \\
\hline & 0.1 & $8.0 \pm 1.0^{b}$ & $34 \%$ \\
\hline & 0.5 & $4.6 \pm 1.0^{b}$ & $20 \%$ \\
\hline & 1 & $3.8 \pm 0.4^{b}$ & $16 \%$ \\
\hline & 2 & $2.7 \pm 0.5$ & $12 \%$ \\
\hline
\end{tabular}

Values are means \pm standard deviation. ${ }^{a} \mathrm{NA}$, not applicable. ${ }^{b}$ Values significantly different from wild type at $\mathrm{P}<0.05$. 

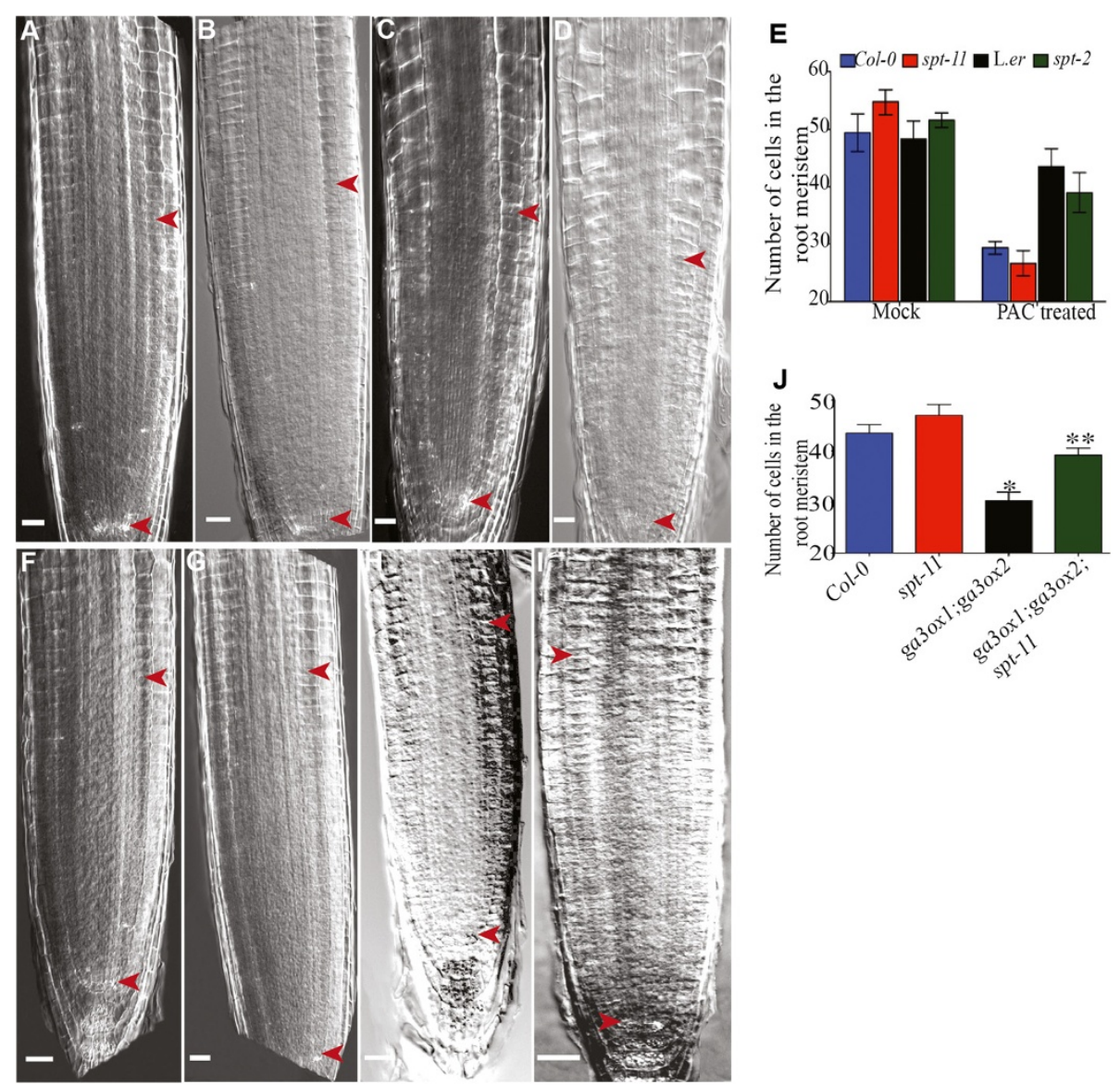

Figure 6 SPT acts additively with GA in the root. (A-D) Micrographs of 8 DAG roots. Arrowheads indicate the zone of cell proliferation. (A, B) Mock treated. (C, D) PAC treated. (A, C) Col-0. (B, D) spt-11. (E) RAM cell number of mock and PAC treated seedlings. Error bars indicate standard error. The values are means of three independent experiments ( $n=15 /$ replicate). (F-I) Micrographs of representative 7 DAG seedlings. Arrowheads indicate the zone of cell proliferation. (F) Col-0. (G) spt-11. (H) ga3ox1-2; ga3ox2-1. (I) ga3ox1-2; ga3ox2-1; spt-11. (J) RAM cell number $(n=15)$. Asterisks and double asterisks indicate values that are significantly different from wild type and ga3ox1-2; ga3ox2-1, respectively. Scale bars indicate $100 \mu \mathrm{m}$.

were higher in spt-2 (Figure 7B). The expression of the GA receptors did not significantly change in the mutants (Figure 7A). Thus, there was not a consistent change in gene expression that would indicate that GA levels or signalling are altered in the spt background.

Since the above expression results were inconclusive, we examined the expression of several downstream GAresponsive genes: SCARECROW-LIKE 3 (SCL3), which is downregulated in response to GA, and EXPANSIN1 (EXP1) and GIBBERELLIC ACID INSENSITIVE (GAI), both of which are increased by GA [56]. Consistent with previous reports, exogenous GA does not significantly increase GA-induced gene expression in the L. er background (Figure 7D; [23]). In the absence of GA application, there was no significant difference in expression of SCL3, EXP1 or GAI between spt-11 or spt-2 and wild type (Figure 7C, D). Upon GA application, the significant increase in EXP1 expression seen in wild type is not observed in spt-11 (Figure 7C), perhaps suggesting that
$S P T$ contributes to regulation of this gene. However, similar to the situation seen with the GA biosynthetic and catabolic genes, no consistent pattern of GA responsive gene expression was seen.

\section{Discussion}

Previous studies have shown that SPT functions in diverse organs of the aerial portion of Arabidopsis, including the cotyledon [23], the leaf [21], the gynoecium $[16,17,57]$, the fruit $[18,19]$ and in germinating seeds [20]. In this study we have shown that SPT also functions in the root, where it acts to restrict RAM size and root length. Loss of function spt mutants have a larger zone of cell division (Figure 1), which contains more dividing cells than wild type (Additional file 2); this leads to a higher growth rate in the roots and longer primary roots. In adult plants, the inflorescence stem is significantly longer than that of wild type and produces more flowers (Table 1). It has previously been shown that 

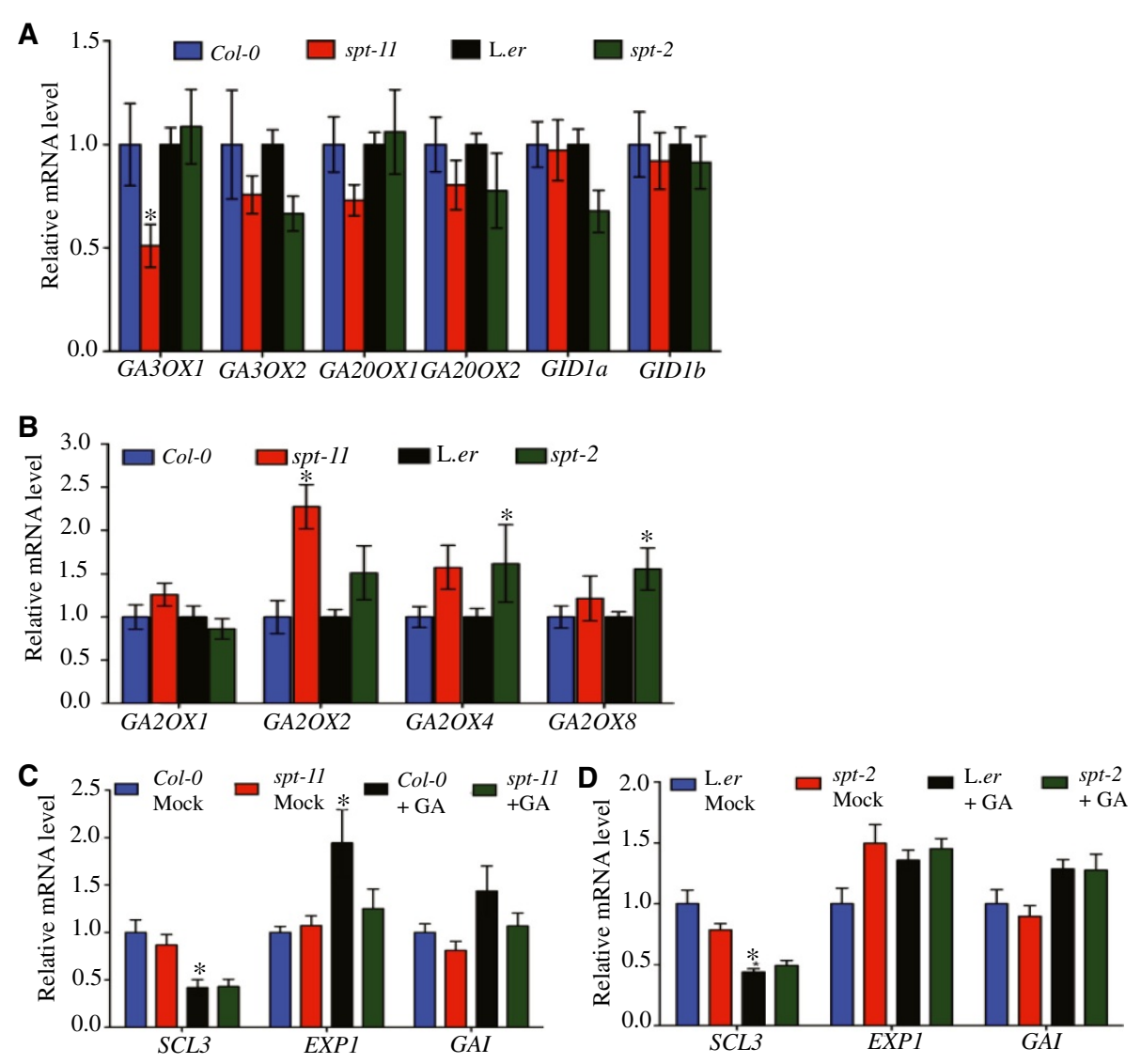

Figure 7 GA-responsive gene expression in the spt background. 7-day-old seedlings were used for gene expression experiments. For analysis of GA-responsive genes, seedlings were treated with 50 $\mathrm{\mu M}$ GA or mock solution for three hours. (A) Expression of GA biosynthesis genes and GA receptor-encoding genes. (B) Expression of GA catabolism genes. (C, D) Expression of GA-responsive genes. Error bars indicate standard error of the means of expression.

spt-11 plants have larger leaf areas due to increased cell number [21] and cotyledon size due to increased cell expansion [23]. Taken together, these data suggest that $S P T$ acts to restrict cell proliferation and expansion in a number of organs in Arabidopsis.

QC size was increased in both spt-2 and spt-11 roots, as assayed by morphology and molecular markers. In the wild type background, the QC consists of on average four cells that are mitotically less active than the surrounding initial cells [1]. However, spt mutants have an increased number of cells in their QCs, often being three or four cells across instead of two and sometimes having two layers of QC cells (Figures 3, 4). The increase in size of the QC is evident in the embryo, starting at approximately torpedo stage (Figure 3). spt-11 embryos can have up to 6 cells in their QC and the size increase continues during root development, as roots with up to $10 \mathrm{QC}$ cells were observed. The increase in the size of the QC and the root division zone in roots of spt mutants is similar to the increase in the size of the meristematic region of leaves in spt mutants [21], suggesting that the molecular pathway in which SPT functions may be similar in these two organs.

SPT expression is correlated with areas of high auxin content $[16,24]$, suggesting a relationship between SPT and auxin. The SPT promoter also contains several auxin response elements (AREs), suggesting that auxin response factors (ARFs) may directly regulate its expression. However, it has previously been shown that mutating these elements does not change expression of a SPT reporter [24]. The increase in size of the RAM seen in spt mutants is correlated with a broader zone of expression of the auxin efflux carrier PIN4 and a stronger auxin maximum, as visualized by DR5::GUS expression (Figure 5). This may result from changes in auxin transport, as seen in developing carpels of spt mutants $[19,30]$, which is supported by the increased sensitivity to NPA shown by spt-11 roots (Table 3). spt carpel defects can be rescued by application of the auxin transport inhibitor NPA [30,57], suggesting that SPT activity may impact auxin transport, which is consistent with its regulation of protein kinases that regulate the PIN efflux 
carriers [19]. However, in the root, spt-11 mutants are hypersensitive to NPA application (Table 3) while in the carpel its application ameliorates the developmental defects caused by loss of SPT. A possible explanation for this could be differences between auxin transport in the carpel and the root tips. Carpel development depends on an auxin gradient along the apical-basal axis of the gynoecium, with the highest level of auxin present in the apex. Root development and growth, however, depends on both on an apical-basal auxin gradient with its greatest concentration in the region of the QC (generated by polar transport through protophloem cells) and redirection of that auxin flow laterally in the root cap where it subsequently flows back toward the shoot (through lateral root cap and epidermal cells) [58]. Disruption of any of these auxin transport pathways impacts root growth and development $[34,59]$. Thus, NPA application on the root tip likely causes more complex changes in auxin flow and accumulation compared to its effect in the carpel. SPT may regulate not only apical-basal auxin transport but also the auxin redirection pathway as well.

Our data, similar to that reported by other groups working on shoot organs [23], suggests that SPT functions in parallel to GA to regulate RAM size and root length. It has long been known that there is crosstalk between auxin and GA and between auxin transport and GA. Recently it has been shown that GA-deficient plants accumulate fewer PIN auxin transport proteins, although PIN4 accumulation was not evaluated, and that this correlates with less auxin transport [60]. Therefore, it is possible that changes in GA content or signalling in $s p t$ mutants might lead to the changes in auxin accumulation at the root tip we observed. Clearly more work is necessary to determine the relationship(s) between GA, auxin and SPT.

As mentioned above, SPT has functions in germination, cotyledon expansion, leaf size and gynoecium development. Our work extends the functions of this gene into the root, where it acts to regulate cell proliferation in the meristematic zone without impacting overall root organization or differentiation in the mature area of the root. This is similar to the role of SPT in leaf growth control, where it appears to act by restricting the size of the basal meristematic zone of the leaf without altering leaf morphology or cell types [21]. This is in contrast to the effect of loss of SPT in the flower, where less cell proliferation takes place in the gynoecium, resulting in a shorter pistil with defects in stigma, style and transmitting tract tissues [17]. However, since SPT may act through regulation of auxin transport in both the carpel and root, the varying impacts on cell proliferation in these organs may be due to differences in auxin response.

SPT encodes a bHLH protein [16] that has been shown to act as a transcriptional activator [61]. bHLH proteins act in dimers or larger order protein complexes. SPT belongs to a subclade of bHLH factors (Group VII of [62]/subfamily 15 of [63]). This group has fourteen members of which the $A L C$ gene, partially redundant with $S P T[18,64]$, is most closely related. These proteins can heterodimerize with each other [18]; however, $A L C$ is not highly expressed in the root (Genevestigator; $[65,66])$. In addition, the PIF/PIL bHLH proteins fall in this clade, which interact with phytochromes and contain a PHYB-binding domain not found in either SPT or ALC $[63,67]$. SPT has been shown to interact genetically with PIL5 during seed germination [20] and PIL5 is known to regulate GA responsiveness [68]. SPT also interacts with PIF6 during pistil development [57], suggesting it may be able to act with the products of these genes to regulate gene expression. However, root expression of these genes is low (Genevestigator; [65,66]). SPT also heterodimerizes with members of the HECATE family of bHLH transcription factors [69]. Loss of these genes causes carpel defects similar to those of $s p t$ mutants and they are expressed in an overlapping pattern with SPT in the carpel, but are not expressed in the root. Additionally, SPT interacts with IND in the carpel and fruit where it may bind DNA cooperatively with that protein [19]; it is unknown if this gene is expressed in roots.

While no bHLH proteins have been shown to interact with SPT in the root to date and its known interactors are not known to be expressed in this organ, at least three genes encoding bHLH transcription factors are active in root growth control. LONESOME HIGHWAY $(L H W)$ regulates the size of the stem cell pool that gives rise to the cells of the root vascular cylinder [40], while UPBEAT1 (UPB1) regulates the expression of peroxidases to modulate the balance of reactive oxygen species between the zone of cell division and the elongation zone, regulating the onset of differentiation [70]. Expression of both of these factors partially overlaps with that of SPT. In addition, MYC2 has been shown to be necessary for the jasmonate-mediated repression of root growth by directly repressing expression of PLT1 and PLT2 [71]. Examination of binding partners of SPT in the root and identification of target genes in this organ will provide great insight into the molecular pathway or pathways in which SPT acts.

\section{Conclusions}

$S P T$ has previously been shown to regulate growth in several above ground organs of Arabidopsis. SPT also regulates proliferation in the root, controlling the size of the RAM and the number of cells in the QC. However, the organization of the root and differentiation of root cell types is not altered, although extra cells are made. $S P T$ regulates growth in parallel to GA and by modifying 
the accumulation of auxin in the region of the QC, likely via regulation of auxin transport.

\section{Methods}

\section{Plant materials and growth conditions}

The spt-2 allele is in the L. er background and has been previously described [17]. The spt-11 allele, a T-DNA insertion line in the Col-0 background, has been previously described [21] and is from the WISCDSLOX collection [72]. Seeds of other mutants used in the study have also been described: ga1-3 [45] and ga3ox1-3; ga3ox2-1 [44]. The double mutant ga1-3; spt-2 was generated by crossing homozygous ga1-3 and homozygous spt-2 plants and allowing the F1 to self-fertilize. The triple mutant ga3ox1-3; ga3ox2-1; spt-11 was generated by crossing homozygous ga3ox1-3; ga3ox2-1 plants and homozygous spt-11 plants and allowing the F1 to selffertilize. Double and triple mutants were identified by PCR genotyping of the segregating F2 population. To generate spt-11 mutants containing marker lines, homozygous spt-11 plants were crossed to the lines (Additional file 6) and the F1 allowed to self-fertilize. Mutants were identified by PCR genotyping of the F3 after growth on antibiotic containing media to select for the transgene.

Arabidopsis thaliana seeds were cold treated for 3 days at $4^{\circ} \mathrm{C}$ and were germinated and grown on Fafard 2 mix soil (Fafard) under long-day (16 hours, $80 \mu \mathrm{mol} \mathrm{m} \mathrm{m}^{-2} \mathrm{~s}^{-1}$ ) irradiance, either in controlled growth chambers (Enconair Ecological Chambers Inc., Manitoba, Canada) or growth rooms with subirrigation at $22^{\circ} \mathrm{C}$ with $60 \%$ relative humidity.

Seeds used in all the assays done on seedlings were sterilized as previously described [73], placed on either on Murashige \& Skoog (MS) media (Research Products International Corporation, Mt. Prospect, IL) with $1 \%$ plant agar in Petri plates or on half GM plates (half concentration of MS salts, $1 \%$ sucrose, $0.8 \%$ Plant agar, $\mathrm{pH}$ 5.7). The plates were incubated in the dark at $4^{\circ} \mathrm{C}$ for 5 days. The plates were then moved to a CU-36L growth chamber (Percival Scientific Inc., Perry, IA), placed vertically and grown under long day conditions as above unless noted.

\section{PCR genotyping}

Mutants were identified by PCR genotyping of genomic DNA. Genomic DNA was extracted from inflorescences and leaves as described previously [73]. Primer sequences are shown in Additional file 7 and combinations used for genotyping various mutants are listed in Additional file 8.

\section{Phenotypic analysis}

In order to analyze various developmental phenotypes of mutants and wild type, plants were grown under long day conditions. Seeds of various genotypes were sown in square cells or pots in a randomized block design. After seeds were germinated, all seedlings except one per cell or pot were weeded out.

Several aerial phenotypes were analyzed as previously described [73]. Leaf number at flowering was defined as the number of leaves when the first flower opened. In order to analyze root phenotypes, plants were grown on vertically oriented plates. For all the measurements done on seedlings in this study, the first day of incubation in the chamber was counted as day zero. Seedlings were collected for analysis at different Days After Germination (DAG) starting at 3 DAG till 11 DAG. To visualize roots using microscopy, seedlings were fixed overnight in ethanol and acetic acid (9:1). Roots were cleared in chloral hydrate ( 80 grams of chloral hydrate, $20 \mathrm{ml}$ of water and $10 \mathrm{ml}$ of glycerol) on microscope slides for 20 minutes for microscopic analysis with Differential Interference Contrast (DIC) optics on a Nikon Eclipse 90i. Pictures were taken using the attached Nikon camera and analyzed with NIS elements Advanced Research software version 3.0. Fifteen seedlings per genotype were used for root meristem size measurement. Root meristem size was measured as the number of cells in the cortical cell layer between the QC and the first elongating cell as described [25] and the results were depicted in graphical format using Prism (http://www.graphpad. com/prism/; GraphPad Software, La Jolla, CA). Results were analyzed statistically using a two-sample student $\mathrm{t}$ test. The length of the meristematic zone was measured in micrometers from the QC to the first elongating cell in the root cortical cell layer as described [25]. Results were analyzed and displayed as above.

In order to determine the effect of PAC (PhytoTechnology Laboratories, Shawnee Mission, KS) on root growth, seedlings were transferred from half GM plates to half GM plates with $10 \mu \mathrm{M}$ PAC or half GM plates with methanol 4 days after germination. The seedlings were grown in the incubator for 96 hours before they were analyzed for root meristem size as above.

The average primary root length was determined using 30 seedlings of each genotype per replicate with 3 replications. Measurements were taken at 7, 10 and 13 DAG. Primary root growth rate was measured by drawing a line at the tip of primary root on the back of the plate every day, starting from 2 DAG. The distance between the two markings was measured with a ruler. The lengths between the two time points were used for obtaining the growth rate per hour (length in $\mathrm{mm} / 24$ hours).

To look at the cellular organization of roots, 5-day-old roots were hand-sectioned according to the protocol "Rapid preparations of transverse sections of plant roots" (http://www.mcdb.lsa.umich.edu/labs/schiefel/protocols. html). The cross-sections were cut perpendicular to the length of the root beginning at the root tip and moving 
towards the base of the root. The root sections were transferred to a Petri dish containing fluorescent brightener 28 (FB 28 Sigma-Aldrich, St. Louis, MO) dissolved in water. Sections were stained for 10 minutes and examined using UV epifluorescence microscopy using a Nikon Eclipse 90i Microscope. 15 seedlings of each genotype were examined and at least 20 sections per seedling were analyzed.

To visualize embryos for microscopy, seeds containing embryos at different stages of development were collected from developing fruits and processed as previously described [36]. Embryos were visualized with DIC optics on a Nikon Eclipse 90i. Pictures were taken using the attached Nikon camera and analyzed with NIS elements Advanced Research software version 3.0.

\section{Gene expression studies}

To examine SPT expression in roots, roots of 7 DAG L. er seedlings grown on plates were collected and stored at -80 . Total RNA from two biological replicates was extracted using the RNeasy Plant Mini Kit (Qiagen, Valencia, CA) according to instructions. During the RNA purification, on column DNase treatment was done using RNase-free DNase (Qiagen) and RNA was also treated with DNase again in solution. 500 ng of RNA was used as template and cDNA synthesis and PCR was done using the SuperScript III One-Step RT-PCR System (Invitrogen by Life Technologies) using $S P T$ and $A C T I N$-specific primers (Additional file 7). For real-time PCR analysis, the Blue Print First Strand cDNA Synthesis Kit (Takara Bio Inc., Otsu, Shiga, Japan) was used with $1 \mu \mathrm{g}$ of total RNA as template to generate cDNA. $0.5 \mu \mathrm{l}$ of cDNA was used in real-time PCR (qPCR) reactions done using the $\mathrm{iQ}^{\mathrm{m}}$ SYBR Green Supermix (BioRad) on a CFX96 $^{\text {tw }}$ Real-Time PCR detection system (BioRad) at the PMGF. A reference gene, At1g13320, was used to normalize the qPCR data [74]. qPCR data was analyzed using CFX96 software and graphs were made using Prism. Primers for qPCR were designed using QuantPrime Q-PCR primer design tool (Additional files 7 and 9; http://www.quantprime.de; [75]).

For gene expression studies on GA response genes, seedlings were collected at 7 DAG and processed as above. Each genotype was represented by three biological replicates. For GA responsive gene expression, 7-day-old seedlings were treated with either $50 \mu \mathrm{M}$ GA or mock in MS liquid media (1X MS salts, 1X Gamborg's B5 Vitamins, 3\% Sucrose with $\mathrm{pH}$ 5.7) for three hours in the incubator under constant light at $22^{\circ} \mathrm{C}$. For quantifying GA biosynthesis and metabolism genes, three biological and two technical replicates were done. A reference gene, At1g13320, was used to normalize the qPCR data for GA biosynthesis and metabolism genes, while another reference gene, At4g33380, was used for normalizing the $\mathrm{qPCR}$ data for $\mathrm{GA}$ responsive genes [74]. Primers were designed as above. Results were analyzed statistically using a non-parametric Wilcoxon rank sum test for GA biosynthesis, catabolism and receptor genes and using a 2-way analysis of variance for GA responsive genes [76,77].

\section{B-glucuronidase and starch staining}

Expression of QC25::GUS was examined as previously described [36]. Photographs were taken using a Nikon Digital Sight DS-5M camera attached to a Nikon SMZ800 dissecting or on a Nikon Eclipse E200 compound microscope. GUS-stained 5-day-old seedlings were used for visualizing starch granule accumulation in the columella root cap cells. Staining for starch granules was done according to [78] in 1\% lugol solution for 3 minutes, rinsed in water, cleared in chloral hydrate and photographed using Nomarski optics on a Nikon Eclipse 90i Microscope.

\section{Confocal microscopy}

Confocal laser microscopy was used for looking at the expression of various cell specific markers tagged with Green Fluorescent Protein (GFP). The cell walls of various stages of embryos and roots were labelled with propidium iodide and were observed according to [36] with a Nikon D-Eclipse C1si Confocal.

\section{NAA and NPA assays}

NAA and NPA assays were done as described in [79]. Briefly, seeds of Col- 0 and spt-11 were sown on MS media with varying concentrations of NAA $(0,1,20,40,60,80$ and $100 \mathrm{nM})$ or NPA $(0,0.1,0.5,1$ and $2 \mu \mathrm{M})$. Seeds were cold treated for two days and then grown vertically as described above. Root length of 8-day-old seedlings was measured as described above. The average data from three independent experiments are presented and at least 20 seedlings were analyzed per genotype per experiment.

\section{Additional files}

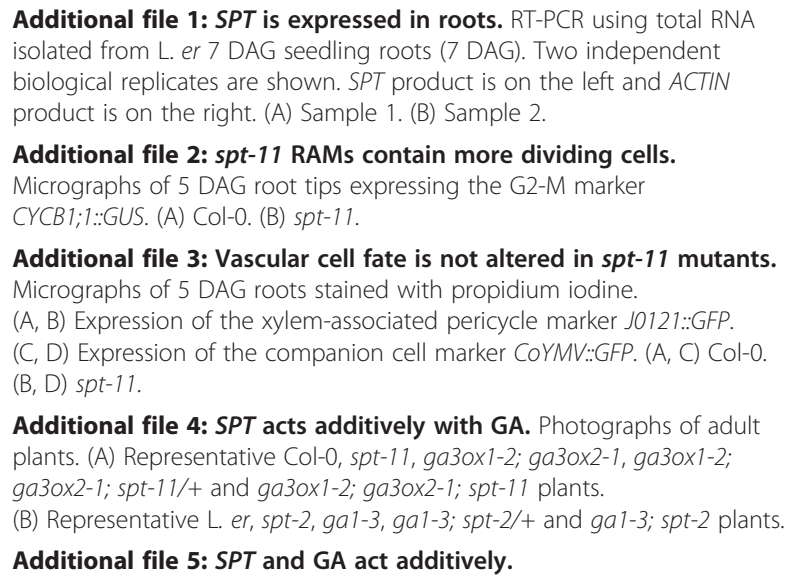

Additional file 2: spt-11 RAMs contain more dividing cells. Micrographs of 5 DAG root tips expressing the G2-M marker CYCB1;1::GUS. (A) Col-0. (B) spt-11.

Additional file 3: Vascular cell fate is not altered in spt-11 mutants. Micrographs of 5 DAG roots stained with propidium iodine.

(A, B) Expression of the xylem-associated pericycle marker J0121::GFP. $(C, D)$ Expression of the companion cell marker CoYMV::GFP. (A, C) Col-0. (B, D) spt-11.

Additional file 4: SPT acts additively with GA. Photographs of adult plants. (A) Representative Col-0, spt-11, ga3ox1-2; ga3ox2-1, ga3ox1-2; ga3ox2-1; spt-11/+ and ga3ox1-2; ga3ox2-1; spt-11 plants.

(B) Representative L. er, spt-2, ga1-3, ga1-3; spt-2/+ and ga1-3; spt-2 plants. Additional file 5: SPT and GA act additively. 


\section{Additional file 6: Marker lines used in this study. \\ Additional file 7: Primers used in this study. \\ Additional file 8: Primer combinations used for genotyping. \\ Additional file 9: Primer combinations used in qRT-PCR.}

\section{Abbreviations}

RAM: Root apical meristem; QC: Quiescent center; PLT1: Plethora1;

PLT2: Plethora2; SHR: Shortroot; SCR: Scarecrow; SPT: Spatula; ALC: Alcatraz; IND: Indehiscent; NPA: Naphthylphthalmic acid; NAA: 1-naphthaleneacetic acid; GA: Gibberellic acid; PAC: Paclobutrozol; L. er: Landsberg erecta; Col-0: Columbia-0; SCL3: Scarecrow-like 3; EXP1: Expansin1; GAl: Gibberellic acid insensitive.

\section{Competing interests}

The authors declare that they have no competing interests.

\section{Authors' contributions}

SM and RSL conceived and designed the experiments. SM performed most of the experiments and analyzed the data. RSL performed the NAA and NPA experiments and RT-PCR on roots. SM and RSL wrote the paper. All authors read and approved the final manuscript.

\section{Acknowledgements}

This work was supported in part by a grant from the National Science Foundation (MCD-0418891) to RSL and funds from The Ohio State University. The authors thank Dr. Patrice Hamel, Dr. JC Jang and Dr. Iris Meier (Ohio State University) and members of the Lamb laboratory for helpful advice on the manuscript and Rachel Edwards for technical assistance.

Received: 16 July 2012 Accepted: 12 December 2012

Published: 2 January 2013

\section{References}

1. Dolan L, Janmaat K, Willemsen V, et al: Cellular organisation of the Arabidopsis thaliana root. Development 1993, 119(1):71-84.

2. Ishikawa H, Evans ML: Specialized zones of development in roots. Plant Physiol 1995, 109:725-727.

3. Scheres B, Wolkenfelt $H$, Willemsen $V$, et al: Embryonic origin of the Arabidopsis primary root and root meristem initials. Development 1994, 120:2475-2487.

4. Mansfield SG, Briarty LG: Early embryogenesis in Arabidopsis thaliana. II. The developing embryo. Can J Bot 1991, 69:461-476.

5. Laux T, Jurgens G: Embryogenesis: A New Start in Life. Plant Cell 1997, 9(7):989-1000

6. Aida M, Beis D, Heidstra R, et al: The PLETHORA genes mediate patterning of the Arabidopsis root stem cell niche. Cell 2004, 119(1):109-120.

7. Galinha C, Hofhuis H, Luijten M, et al: PLETHORA proteins as dosedependent master regulators of Arabidopsis root development. Nature 2007, 449(7165):1053-1057.

8. Benfey PN, Linstead PJ, Roberts K, et al: Root development in Arabidopsis: four mutants with dramatically altered root morphogenesis. Development 1993, 119(1):57-70.

9. Di Laurenzio L, Wysocka-Diller J, Malamy JE, et al: The SCARECROW gene regulates an asymmetric cell division that is essential for generating the radial organization of the Arabidopsis root. Cell 1996, 86(3):423-433.

10. Helariutta Y, Fukaki H, Wysocka-Diller J, et al: The SHORT ROOT gene controls radial patterning of the Arabidopsis root through radial signaling. Cell 2000, 101:555-567.

11. Nakajima K, Sena G, Nawy T, Benfey PN: Intercellular movement of the putative transcription factor SHR in root patterning. Nature 2001, 413(6853):307-311

12. Cui $H$, Levesque MP, Vernoux $T$, et al: An evolutionarily conserved mechanism delimiting SHR movement defines a single layer of endodermis in plants. Science 2007, 316(5823):421-425.

13. Levesque MP, Vernoux T, Busch W, et al: Whole-genome analysis of the SHORT-ROOT developmental pathway in Arabidopsis. PLOS Biol 2006, 4(5):e143.
14. Sabatini S, Heidstra R, Wildwater M, Scheres B: SCARECROW is involved in positioning the stem cell niche in the Arabidopsis root meristem. Genes Dev 2003, 17(3):354-358.

15. Heidstra $R$, Welch D, Scheres B: Mosaic analyses using marked activation and deletion clones dissect Arabidopsis SCARECROW action in asymmetric cell division. Genes Dev 2004, 18(16):1964-1969.

16. Heisler MG, Atkinson A, Bylstra YH, et al: SPATULA, a gene that controls development of carpel margin tissues in Arabidopsis, encodes a bHLH protein. Development 2001, 128(7):1089-1098.

17. Alvarez J, Smyth DR: CRABS CLAW and SPATULA, two Arabidopsis genes that control carpel development in parallel with AGAMOUS. Development 1999, 126(11):2377-2386.

18. Groszmann M, Paicu T, Alvarez JP, et al: SPATULA and ALCATRAZ, are partially redundant, functionally diverging $\mathrm{bH} \mathrm{H} \mathrm{H}$ genes required for Arabidopsis gynoecium and fruit development. Plant J 2011, 68(5):816-829.

19. Girin T, Paicu T, Stephenson P, et al: INDEHISCENT and SPATULA Interact to Specify Carpel and Valve Margin Tissue and Thus Promote Seed Dispersal in Arabidopsis. Plant Cell 2011, 23(10):3641-3653.

20. Penfield $\mathrm{S}$, Josse EM, Kannangara $R$, et al: Cold and light control seed germination through the bHLH transcription factor SPATULA. Curr Biol 2005, 15(22):1998-2006.

21. Ichihashi Y, Horiguchi G, Gleissberg S, Tsukaya H: The bHLH transcription factor SPATULA controls final leaf size in Arabidopsis thaliana. Plant Cell Physiol 2010, 51(2):252-261.

22. Sidaway-Lee $\mathrm{K}$, Josse EM, Brown $A$, et al: SPATULA links daytime temperature and plant growth rate. Curr Biol 2010, 20(16):1493-1497.

23. Josse EM, Gan Y, Bou-Torrent J, et al: A DELLA in Disguise: SPATULA Restrains the Growth of the Developing Arabidopsis Seedling. Plant Cell 2011, 23(4):1337-1351.

24. Groszmann M, Bylstra Y, Lampugnani ER, Smyth DR: Regulation of tissuespecific expression of SPATULA, a bHLH gene involved in carpel development, seedling germination, and lateral organ growth in Arabidopsis. J Exp Bot 2010, 61(5):1495-1508.

25. Achard P, Gusti A, Cheminant S, et al: Gibberellin signaling controls cell proliferation rate in Arabidopsis. Curr Biol 2009, 19(14):1188-1193.

26. Colon-Carmona A, You R, Haimovitch-Gal T, Doerner P: Technical advance: spatio-temporal analysis of mitotic activity with a labile cyclin-GUS fusion protein. Plant J 1999, 20(4):503-508.

27. Rutherford R, Masson PH: Arabidopsis thaliana sku mutant seedlings show exaggerated surface-dependent alteration in root growth vector. Plant Physiol 1996, 111(4):987-998.

28. Bechtold N, Ellis J, Pelletier G: In planta Agrobacterium mediated gene transfer by infiltration of adult Arabidopsis plants. C R Acad Sci Ser III Sci Vie 1993, 316:1194-1199.

29. Sabatini $\mathrm{S}$, Beis $\mathrm{D}$, Wolkenfelt $\mathrm{H}$, et al: An auxin-dependent distal organizer of pattern and polarity in the Arabidopsis root. Cell 1999, 99(5):463-472.

30. Nemhauser JL, Feldman LJ, Zambryski PC: Auxin and ETTIN in Arabidopsis gynoecium morphogenesis. Development 2000, 127(18):3877-3888.

31. Friml J, Benkova E, Blilou I, et al: AtPIN4 mediates sink-driven auxin gradients and root patterning in Arabidopsis. Cell 2002, 108(5):661-673.

32. Ni DA, Wang $L J$, Ding $C H, X u Z H$ : Auxin distribution and transport during embryogenesis and seed germination of Arabidopsis. Cell Res 2001, 11(4):273-278

33. Lucas M, Swarup R, Paponov IA, et al: Short-Root regulates primary, lateral, and adventitious root development in Arabidopsis. Plant Physiol 2011, 155(1):384-398.

34. Vieten A, Vanneste S, Wisniewska J, et al: Functional redundancy of PIN proteins is accompanied by auxin-dependent cross-regulation of PIN expression. Development 2005, 132(20):4521-4531.

35. Peer WA, Bandyopadhyay A, Blakeslee JJ, et al: Variation in expression and protein localization of the PIN family of auxin efflux facilitator proteins in flavonoid mutants with altered auxin transport in Arabidopsis thaliana. Plant Cell 2004, 16(7):1898-1911.

36. Teotia S, Lamb RS: RCD1 and SRO1 are necessary to maintain meristematic fate in Arabidopsis thaliana. J Exp Bot 2011, 62(3):1271-1284.

37. Wysocka-Diller JW, Helariutta Y, Fukaki $\mathrm{H}$, et al: Molecular analysis of SCARECROW function reveals a radial patterning mechanism common to root and shoot. Development 2000, 127(3):595-603.

38. Malamy JE, Benfey PN: Analysis of SCARECROW expression using a rapid system for assessing transgene expression in Arabidopsis roots. Plant $J$ 1997, 12(4):957-963. 
39. Brady SM, Orlando DA, Lee JY, et al: A high-resolution root spatiotemporal map reveals dominant expression patterns. Science 2007, 318(5851):801-806.

40. Ohashi-Ito K, Bergmann DC: Regulation of the Arabidopsis root vascular initial population by LONESOME HIGHWAY. Development 2007. 134(16):2959-2968.

41. Matsuda $Y$, Liang G, Zhu Y, et al: The Commelina yellow mottle virus promoter drives companion-cell-specific gene expression in multiple organs of transgenic tobacco. Protoplasma 2002, 220(1-2):51-58.

42. Ubeda-Tomas S, Federici F, Casimiro I, et al: Gibberellin signaling in the endodermis controls Arabidopsis root meristem size. Curr Biol 2009, 19(14):1194-1199.

43. Ubeda-Tomas S, Swarup R, Coates J, et al: Root growth in Arabidopsis requires gibberellin/DELLA signalling in the endodermis. Nat Cell Biol 2008, 10(5):625-628.

44. Mitchum MG, Yamaguchi S, Hanada A, et al: Distinct and overlapping roles of two gibberellin 3-oxidases in Arabidopsis development. Plant J 2006, 45(5):804-818.

45. Silverstone AL, Chang C, Krol E, Sun TP: Developmental regulation of the gibberellin biosynthetic gene GA1 in Arabidopsis thaliana. Plant J 1997, 12(1):9-19.

46. Yamaguchi S: Gibberellin metabolism and its regulation. Annu Rev Plant Biol 2008, 59:225-251.

47. Chiang HH, Hwang I, Goodman HM: Isolation of the Arabidopsis GA4 locus. Plant Cell 1995, 7(2):195-201.

48. Matsushita A, Furumoto T, Ishida S, Takahashi Y: AGF1, an AT-hook protein, is necessary for the negative feedback of AtGA3ox1 encoding GA 3-oxidase. Plant Physiol 2007, 143(3):1152-1162.

49. Phillips AL, Ward DA, Uknes $S$, et al: Isolation and expression of three gibberellin 20-oxidase cDNA clones from Arabidopsis. Plant Physiol 1995, 108(3):1049-1057.

50. Xu YL, Li L, Gage DA, Zeevaart JA: Feedback regulation of GA5 expression and metabolic engineering of gibberellin levels in Arabidopsis. Plant Cell 1999, 11(5):927-936.

51. Yamaguchi $\mathrm{S}$, Sun $T$, Kawaide $H$, Kamiya Y: The GA2 locus of Arabidopsis thaliana encodes ent-kaurene synthase of gibberellin biosynthesis. Plant Physio/ 1998, 116(4):1271-1278.

52. Rieu I, Eriksson S, Powers SJ, et al: Genetic analysis reveals that C19-GA 2-oxidation is a major gibberellin inactivation pathway in Arabidopsis. Plant Cell 2008, 20(9):2420-2436.

53. Coles JP, Phillips AL, Croker SJ, et al: Modification of gibberellin production and plant development in Arabidopsis by sense and antisense expression of gibberellin 20-oxidase genes. Plant J 1999, 17(5):547-556.

54. Thomas SG, Phillips AL, Hedden P: Molecular cloning and functional expression of gibberellin 2- oxidases, multifunctional enzymes involved in gibberellin deactivation. Proc Natl Acad Sci USA 1999, 96(8):4698-4703.

55. Griffiths J, Murase K, Rieu I, et al: Genetic characterization and functional analysis of the GID1 gibberellin receptors in Arabidopsis. Plant Cell 2006, 18(12):3399-3414.

56. Ogawa M, Hanada A, Yamauchi Y, et al: Gibberellin biosynthesis and response during Arabidopsis seed germination. Plant Cell 2003, 15(7):1591-1604.

57. Foreman J, White J, Graham I, et al: Shedding light on flower development: phytochrome $B$ regulates gynoecium formation in association with the transcription factor SPATULA. Plant Signal Behav 2011, 6(4):471-476

58. Wisniewska J, Xu J, Seifertova D, et al: Polar PIN localization directs auxin flow in plants. Science 2006, 312(5775):883.

59. Laxmi A, Pan J, Morsy M, Chen R: Light plays an essential role in intracellular distribution of auxin efflux carrier PIN2 in Arabidopsis thaliana. PLoS One 2008, 3(1):e1510.

60. Willige $B C$, Isono E, Richter $R$, et al: Gibberellin Regulates PIN-FORMED Abundance and Is Required for Auxin Transport-Dependent Growth and Development in Arabidopsis thaliana. Plant Cell 2011, 23(6):2184-2195.

61. Groszmann M, Paicu T, Smyth DR: Functional domains of SPATULA, a bHLH transcription factor involved in carpel and fruit development in Arabidopsis. Plant J 2008, 55(1):40-52

62. Heim MA, Jakoby M, Werber $M$, et al: The basic helix-loop-helix transcription factor family in plants: a genome-wide study of protein structure and functional diversity. Mol Biol Evol 2003, 20(5):735-747.

63. Toledo-Ortiz G, Huq E, Quail PH: The Arabidopsis basic/helix-loop-helix transcription factor family. Plant Cell 2003, 15(8):1749-1770.
64. Rajani S, Sundaresan V: The Arabidopsis myc/bHLH gene ALCATRAZ enables cell separation in fruit dehiscence. Curr Biol 2001, 11(24):1914-1922.

65. Zimmermann P, Hennig L, Gruissem W: Gene-expression analysis and network discovery using Genevestigator. Trends Plant Sci 2005, 10(9):407-409.

66. Zimmermann P, Hirsch-Hoffmann M, Hennig L, Gruissem W: GENEVESTIGATOR. Arabidopsis microarray database and analysis toolbox. Plant Physiol 2004, 136(1):2621-2632.

67. Ni M, Tepperman JM, Quail PH: PIF3, a phytochrome-interacting factor necessary for normal photoinduced signal transduction, is a novel basic helix-loop-helix protein. Cell 1998, 95(5):657-667.

68. Oh E, Yamaguchi $\mathrm{S}, \mathrm{Hu}$ J, et al: PIL5, a phytochrome-interacting bHLH protein, regulates gibberellin responsiveness by binding directly to the GAI and RGA promoters in Arabidopsis seeds. Plant Cell 2007, 19(4):1192-1208.

69. Gremski K, Ditta G, Yanofsky MF: The HECATE genes regulate female reproductive tract development in Arabidopsis thaliana. Development 2007, 134(20):3593-3601.

70. Tsukagoshi H, Busch W, Benfey PN: Transcriptional regulation of ROS controls transition from proliferation to differentiation in the root. Cell 2010, 143(4):606-616.

71. Chen Q, Sun J, Zhai Q, et al: The Basic Helix-Loop-Helix Transcription Factor MYC2 Directly Represses PLETHORA Expression during JasmonateMediated Modulation of the Root Stem Cell Niche in Arabidopsis. Plant Cell 2011, 23(9):3335-3352.

72. Woody ST, Austin-Phillips S, Amasino RM, Krysan PJ: The WiscDsLox T-DNA collection: an arabidopsis community resource generated by using an improved high-throughput T-DNA sequencing pipeline. J Plant Res 2007, 120(1):157-165.

73. Teotia S, Lamb RS: The paralogous genes RADICAL-INDUCED CELL DEATH1 and SIMILAR TO RCD ONE1 have partially redundant functions during Arabidopsis development. Plant Physiol 2009, 151(1):180-198.

74. Czechowski T, Stitt M, Altmann T, et al: Genome-wide identification and testing of superior reference genes for transcript normalization in Arabidopsis. Plant Physio/ 2005, 139(1):5-17.

75. Arvidsson S, Kwasniewski M, Riano-Pachon DM, Mueller-Roeber B: QuantPrime-a flexible tool for reliable high-throughput primer design for quantitative PCR. BMC Bioinforma 2008, 9:465.

76. Yuan JS, Reed A, Chen F, Stewart CN Jr: Statistical analysis of real-time PCR data. BMC Bioinforma 2006, 7:85.

77. Goni R, Garcia P, Foissac S: The aPCR data statistical analysis, Integromics White Paper. Tres Cantos: Integromics; 2009:1-9.

78. Willemsen $\mathrm{V}$, Wolkenfelt $\mathrm{H}$, de Vrieze $\mathrm{G}$, et al: The HOBBIT gene is required for formation of the root meristem in the Arabidopsis embryo. Development 1998, 125(3):521-531.

79. Wang $Y$, Lin WH, Chen X, Xue HW: The role of Arabidopsis 5PTase13 in root gravitropism through modulation of vesicle trafficking. Cell Res 2009, 19(10):1191-1204.

doi:10.1186/1471-2229-13-1

Cite this article as: Makkena and Lamb: The bHLH transcription factor SPATULA regulates root growth by controlling the size of the root meristem. BMC Plant Biology 2013 13:1.

\section{Submit your next manuscript to BioMed Central and take full advantage of:}

- Convenient online submission

- Thorough peer review

- No space constraints or color figure charges

- Immediate publication on acceptance

- Inclusion in PubMed, CAS, Scopus and Google Scholar

- Research which is freely available for redistribution 